\title{
GASTROINTESTINAL AND NEUROLOGICAL MANIFESTATIONS IN SYSTEMIC LUPUS ERYTHEMATOSUS
}

\author{
Gina GHEORGHE ${ }^{1,2}$, Gabriela CEOBANU ${ }^{1}$, Madalina ILIE ${ }^{1,2}$, Ana Maria A. STANESCU ${ }^{2}$, \\ Ovidiu G. BRATU ${ }^{2,3}$, Camelia C. DIACONU ${ }^{1,2} \bowtie$ \\ ${ }^{1}$ Clinical Emergency Hospital of Bucharest, Bucharest, Romania \\ ${ }^{2}$ University of Medicine and Pharmacy „Carol Davila“, Bucharest, Romania \\ ${ }^{3}$ Emergency Universitary Central Military Hospital, Academy of Romanian Scientists, Bucharest, Romania
}

Received 09 May 2019, Accepted 15 July 2019

https://doi.org/10.31688/ABMU.2019.54.3.23

\section{Abstract}

Systemic lupus erythematosus (SLE) is a chronic autoimmune disease with unknown etiology and incompletely elucidated pathogenesis. It implies the loss of tolerance to the inner self, which leads to perturbations in the immune system, with production of autoantibodies. SLE is characterized by multisystem involvement, the evolution of these patients being directly influenced by the severity of organ complications. The most common pattern seen in patients with SLE is a combination of musculoskeletal, skin, renal, central nervous system, cardiovascular, hematologic and gastrointestinal manifestations. The gastrointestinal symptoms are commonly seen in patients with SLE, the main pathological mechanisms involved being mesenteric vasculitis, intestinal pseudo-obstruction and protein losing enteropathy. Neurological manifestations are also frequent among these patients and they correlate with a high rate of morbidity and mortality. This review aims to analyze the correlation between gastrointestinal and neurological manifestations in SLE and their impact on the quality of life.

\section{RÉSUMÉ}

Manifestations gastro-intestinales et neurologiques dans le lupus érythémateux systémique

Le lupus érythémateux systémique (LES) est une maladie auto-immune chronique d'étiologie inconnue et de pathogenèse incomplètement élucidée. Cela implique la perte de tolérance envers soi-même,ce qui entraîne des perturbations du système immunitaire, avec la production d'autoanticorps. Le LES est caractérisé par une implication multisystémique, l'évolution de ces patients étant directement influencée par la gravité des complications organiques. Le schéma le plus courant observé chez les patients atteints de LES est une combinaison de manifestations musculosquelettiques, cutanées, rénales, du système nerveux central, cardiovasculaires, hématologiques et gastro-intestinales. Des symptômes gastro-intestinaux sont fréquemment observés chez les patients atteints de LES, les principaux mécanismes pathologiques impliqués étant une vascularite mésentérique, une pseudo-obstruction intestinale et une entéropathie avec perte de protéines. 
Keywords: systemic lupus erythematosus, autoantibodies, gastrointestinal manifestations, neurological manifestations.
Les manifestations neurologiques sont également courantes chez ces patients et elles sont corrélées à un taux élevé de morbidité et de mortalité. Cette revue a pour objectif d'analyser la corrélation entre les manifestations gastro-intestinales et neurologiques dans le LES et leur impact sur la qualité de vie.

Mots-clés: lupus érythémateux systémique, autoanticorps, manifestations gastro-intestinales, manifestations neurologiques.

reported a threefold increase in SLE incidence in the last 40 years, which most certainly is not attributed only to the perfection of the diagnostic tools ${ }^{4,5}$. The frequency of SLE is ten times higher among women; multiple mechanisms have so far been incriminated: estrogen hormonal effects, pregnancy, gene variants located on X chromosome, chronobiologic differences and menstruation ${ }^{5}$. On the other hand, SLE that occurs in men is slightly different from that in women, being reported that men usually have worse outcomes ${ }^{5}$. The predilection of SLE for young women is well documented; $65 \%$ of patients have disease onset between the ages of 16 and 55, median ages at diagnosis ranging from 37 to 50 years ${ }^{5}$.

Table 1. SLICC Classification Criteria for Systemic Lupus Erythematosus

\begin{tabular}{ll}
\hline \multicolumn{1}{c}{ Clinical Criteria } & \multicolumn{1}{c}{ Immunologic criteria } \\
\hline 1. Acute cutaneous lupus & 1. ANA \\
2. Chronic cutaneous lupus & 2. Anti-DNA antibodies \\
3. Oral or nasal ulcers & 3. Anti-Sm antibodies \\
4. Non-scarring alopecia & 4. Antiphospholipid antibody \\
5. Arthritis & 5. Low complement (C3, C4, CH50) \\
6. Serositis & 6. Direct Coombs' test (do not count in the presence of \\
7. Renal & hemolytic anemia) \\
8. Neurologic & \\
9. Hemolytic anemia & \\
10. Leukopenia & \\
11. Thrombocytopenia $(<100.000 / \mathrm{mmc})$ &
\end{tabular}

Legend: ANA=anti-nuclear antibodies; Anti-DNA Antibodies = Anti-deoxyribonucleic acid Antibodies; Anti-Sm Antibodies =Anti-Smith Antibodies.

Table 2. Associations between clinical manifestations and the presence of specific antibodies seen in patients with SLE.

\begin{tabular}{cc}
\hline Antibodies & Clinical manifestations \\
\hline Anti-DNA & Nephritis \\
\hline Anti-histones & Drug-induced SLE \\
\hline Anti-Ro (SS-A) & Cutaneous manifestations \\
Anti-La (SS-B) & Neonatal lupus \\
\hline Anti-Sm & Nephritis \\
\hline Anti-U1RNP & Arthritis, Raynaud's phenomenon \\
\hline Anti-ribosomal P protein & Psychosis \\
\hline Anti-phospholipids & Thrombosis, miscarriage \\
\hline
\end{tabular}


Despite numerous research studies aiming to elucidate the etiology of SLE, it continues to remain unclear. Genetic, immunologic, hormonaland environmental factors have been considered to have an important role in setting the stage of the disease $e^{4,5}$.

Clinical and biological manifestations of SLE are the result of cellular destruction triggered by autoantibodies, either by cytotoxic reactions or by participating in the formation of immune complexes. The clinical heterogeneity of SLE as well as the absence of pathognomonic elements pose a challenge in the diagnosis of the disease ${ }^{7}$. When making the diagnosis of SLE, clinicians refer to the Systemic Lupus International Collaborating Clinics (SLICC) classification criteria revised in 2012 (Table 1) ${ }^{8}$.

The positive diagnosis is based on the presence of at least 4 criteria (at least one clinical and one laboratory criteria) or biopsy-proven lupus nephritis with positive ANA or Anti-DNA .

Serological anomalies include multiple autoantibodies with associations being identified between clinical manifestations and the presence of specific antibodies (Table 2) .

\section{Clinical manifestations in SLE}

The clinical manifestations of SLE (Table 3) vary significantly due to multiple organ affected ${ }^{4,9,10}$. As a result of chronic inflammation, patients with SLE can present general symptoms such as fever, anorexia, asthenia and weight loss.

\section{Gastrointestinal manifestations in SLE}

Gastrointestinal symptoms are common among patients with SLE, being first described by Sir William Osler in $1895^{15}$. Pathogenically speaking, they are rarely a result of the direct damage to the gastrointestinal tract caused by the chronic inflammatory processes characteristic to SLE ${ }^{2}$. Thus, in more than half of the cases, digestive symptoms are secondary to adverse drug reactions, viral infections, bacterial infections and other intercurrent processes, such as uremia ${ }^{16,17}$. So far, no specific antibodies were identified in lupus-induced gastroenteropathy ${ }^{16}$.

These symptoms can occur at any age, but are most commonly found in women of childbearing age, in-between puberty and menopause ${ }^{18}$.

Table 3. Clinical manifestations of SLE.

\begin{tabular}{|c|c|}
\hline $\begin{array}{l}\text { Skin and mucous membrane } \\
\text { involvement }^{9}\end{array}$ & $\begin{array}{l}\text { Facial eruption (butterfly rash), maculopapular lesions, discoid lesions, photosensitivity, } \\
\text { Raynaud's phenomenon, generalized or focal alopecia, and others. }\end{array}$ \\
\hline Musculoskeletal involvement ${ }^{10}$ & $\begin{array}{l}\text { arthralgias, arthritis, Jaccoud's syndrome, spontaneous tendon rupture, crystalline } \\
\text { arthropathies, subcutaneous calcifications, inflammatory myopathy }\end{array}$ \\
\hline $\begin{array}{l}\text { Cardiopulmonary involve- } \\
\text { ment }^{11}\end{array}$ & $\begin{array}{l}\text { Pericardial effusion, pericarditis, heart failure, myocarditis, endocarditis (infectious and } \\
\text { non-infectious), atrioventricular block, sinus tachycardia, stable angina, acute coronary } \\
\text { syndrome }\end{array}$ \\
\hline Renal involvement ${ }^{12}$ & $\begin{array}{l}\text { Lupus nephritis: } \\
\text { - Minimal mesangial lupus nephritis (class I) } \\
\text { - Mesangial proliferative lupus nephritis (class II) } \\
\text { - Focal lupus nephritis (class III) } \\
\text { - Diffuse lupus nephritis (class IV) } \\
\text { - Lupus membranous nephropathy (class V) } \\
\text { - Advanced sclerosing lupus nephritis (class VI) } \\
\text { tubulointerstitial nephritis, vascular disease, thrombotic microangiopathy, glomerular } \\
\text { podocytopathy (lupus podocytopathy), collapsing glomerulosclerosis }\end{array}$ \\
\hline Obstetric involvement ${ }^{4}$ & recurrent miscarriages \\
\hline Pulmonary involvement ${ }^{13}$ & $\begin{array}{l}\text { Pleural effusions, acute lupus pneumonitis, pulmonary hemorrhage, various idiopathic } \\
\text { interstitial pneumonias, thromboembolic disease, pulmonary hypertension, shrinking } \\
\text { lung syndrome, lung infection, chest wall pain }\end{array}$ \\
\hline Ocular involvement ${ }^{14}$ & $\begin{array}{l}\text { Discoid lupus-type rash over the eyelids, conjunctivitis, dry eye syndrome, scleritis, ante- } \\
\text { rior uveitis, lupus retinopathy (cotton wool spots, intraretinal hemorrhages, and vascular } \\
\text { tortuosity), central serous chorioretinopathy, optic nerve involvement }\end{array}$ \\
\hline Gastrointestinal involvement ${ }^{17}$ & $\begin{array}{l}\text { esophageal motility disorders, gastroesophageal reflux disease, esophagitis, gastric ulcer, } \\
\text { intestinal pseudo-obstruction, protein-losing enteropathy, hepatomegaly, elevated liver } \\
\text { enzymes, alkaline phosphatase, jaundice, splenomegaly, acute pancreatitis, mesenteric } \\
\text { vasculitis, peritonitis and ascites }\end{array}$ \\
\hline Neurological involvement ${ }^{4}$ & Cognitive dysfunction, strokes, seizures, headache, peripheral neuropathy, and others \\
\hline General & \\
\hline
\end{tabular}


SLE can affect any segment of the digestive system, from the oral cavity and the esophagus to the colon, liver or pancreas:

- Damage to the oral cavity can occur through oral ulcers that are typically painless and involve the upper palate ${ }^{2}$.

- Damage to the esophagus can manifest itself by dysphagia, which is the most common digestive complaint of patients with SLE. Patients may also associate retro-sternal chest pain, heartburn, acid regurgitation or a sore throat. The implied mechanisms are: esophageal motility disorders, gastroesophageal reflux disease, infections (such as Candida, Cytomegalovirus) or drug esophagitis ${ }^{17,19}$.

- Damage to the stomach may result in gastric ulcer when patients can accuse epigastric pain, a feeling of plenitude, early satiety or nausea. They may also be asymptomatic or can go as far as gastrointestinal complications such as bleeding, obstruction, perforation, penetration or fistulization ${ }^{17}$. It is well-known that SLE is a risk factor for stomach ulcers, independent of other causes such as non-steroidal anti-inflammatory treatment or an infection with Helicobacter pylori.

- Damage to the small intestine and colon may be manifested by intestinal pseudo-obstruction, or protein-losing enteropathy. Intestinal pseudo-obstruction is a rare complication of SLE, which usually occurs during disease activity. It is characterized by the presence of signs and symptoms of mechanical bowel obstruction, such as abdominal pain, flatulence or vomiting in the absence of anatomical lesions ${ }^{17}$. The responsible mechanisms are the deposits of immune complexes in the smooth muscle cells and chronic ischemia or vasculitis and hypomotility ${ }^{17,20}$. Protein-losing enteropathy is characterized by the occurrence of hypoalbuminemia and edema in the absence of nephrotic proteinuria. Also, about $50 \%$ of patients have severe diarrhea ${ }^{21}$.

- Damage to the liver and spleen, although considered rare, has been shown in recent studies to be much more common than previously thought ${ }^{4}$. Possible causes include: steatosis, drug toxicity, hepatitis, vascular thrombosis ${ }^{22}$ and coexistence with primary biliary cirrhosis or autoimmune hepatitis ${ }^{23}$. Patients may have hepatomegaly, elevated liver enzymes, alkaline phosphatase, or jaundice ${ }^{17}$. They might also present splenomegaly following a periarterial fibrosis or splenic infarction ${ }^{4}$.

- Damage to the pancreas: Acute pancreatitis occurs in $2-8 \%$ of patients with SLE ${ }^{24}$. Some of the responsible mechanisms include vasculitis, antiphospholipid antibodies-associated thrombosis, deposits of immune complexes and intimal thickening by side effects of azathioprine ${ }^{24,25}$. Some studies suggest a possible correlation between the presence of anti-La antibodies and the risk of pancreatitis ${ }^{2}$.

- Other gastrointestinal disorders: mesenteric vasculitis, peritonitis and ascites.

Mesenteric vasculitis is a serious complication that can be life-threatening. Chronic ischemia can occur insidiously with postprandial abdominal pain, nausea, vomiting or diarrhea. In the case of thrombosis due to mesenteric infarction, the patient can present an acute abdomen, to which there is a risk of perforation and peritonitis ${ }^{17}$. Primary peritonitis secondary to SLE can also be chronic or acute. The acute form can occur in an exacerbation of disease activity, presenting the clinical picture of a surgical acute abdomen, or may be masked by the concurrent use of immunosuppressive drugs. In contrast, chronic peritonitis develops insidiously and may go unnoticed for a long time ${ }^{17,26}$. Ascites is rare among patients with SLE. Its other possible causes may be congestive heart failure, nephrotic syndrome, hypoalbuminemia, or enteropathy secondary to loss of protein ${ }^{27-29}$.

From a therapeutic point of view, most of these gastrointestinal complications have good responses to steroids or immunosuppressive therapy. Also, supportive measures, such as fasting and nutritional support, antibiotics or prokinetics are useful to facilitate functional recovery ${ }^{16}$.

\section{Neurological manifestations in SLE}

Nervous system involvement causes one of the severe manifestations in SLE; it is seen in $10-80 \%$ of patients either prior to the diagnosis or during the course of the disease ${ }^{4,30}$. SLE may affect the nervous system at multiple levels, leading to various neurologic and psychiatric syndromes ${ }^{31}$; they may be classified as primary neurologic and psychiatric disease or secondary disease ${ }^{30}$. The latter is a more common cause of neuropsychiatric symptoms and can be produced by various mechanisms such as active central nervous system (CNS) lupus, sequelae of lupus that is now inactive, complications of chronic LES, complications of other organ system involvement and complications of treatment ${ }^{30}$.

The neuropsychiatric syndromes are the result of the interaction of multiple factors: vasculitis, autoantibodies (anti-neuronal antibodies, antiphospholipid antibodies, lymphocyte toxic antibodies) and accelerated atherosclerosis ${ }^{4}$. Vasculitis was initially thought to be responsible for the neurological manifestations in SLE but investigators found that true vasculitis was a rare finding in these patients ${ }^{31,32}$. However, vasculopathy is seen in many patients and it may cause direct injury, thus affecting the blood-brain barrier and allowing antibodies to enter the nervous system ${ }^{30}$. 
Secondary factors such as infections associated with immunosuppressive therapy, metabolic complications of other organ system failure, hypertension and toxic effects of therapy (particularly corticosteroids) have been considered to play an important role in causing neurologic episodes ${ }^{33}$.

The most common neurologic manifestations of SLE are cognitive dysfunction, stroke, seizures, headaches, and peripheral neuropathy ${ }^{30}$.

- Cognitive dysfunction is frequently seen in patients with SLE and it implies affecting mental activities such as memory, abstract thinking and judgment. Deficits in the cognitive function may be present in 20 to 80 percent of patients ${ }^{30}$.

- Stroke: $19 \%$ of patients with SLE can develop a stroke during the course of the disease, baseline disease activity, hyperlipidemia, and hypertension being identified as risk factors for stroke ${ }^{34}$. Increased risk of stroke was demonstrated among patients of younger age $\mathrm{e}^{35}$ and patients with persistent elevated antiphospholipid antibodies of different specificities ${ }^{36,37}$.

- Seizures may be the first manifestation of lupus and they may be present in up to $20 \%$ of patients with $\mathrm{SLE}^{2}$. Patients can present with both generalized and partial seizures (complex or simple); various contributing factors have been identified: metabolic disturbances, hypertension, infections, tumors, head trauma, stroke, medication withdrawal ${ }^{38,39}$.

- Headache is a frequent symptom in patients with SLE, migraine and tension headache being the most common. Regarding the mechanism of headache, none was identified and no correlation between headache and the disease status has been established.

- Peripheral neuropathy is also a common manifestation in SLE, seen in $15 \%$ of patients ${ }^{40}$. Most of the times it is asymmetric, sensory nerves are affected more than motor nerves and more than one nerve may be damaged ${ }^{40}$. In a few case reports, patients presented with inflammatory polyradiculoneuropathy, including the acute form resembling Guillain-Barré syndrome and the chronic form resembling chronic inflammatory demyelinating polyradiculoneuropathy (CIPD) $)^{40,41}$.

\section{The correlation betweEn NeUROLogical and GASTROINTESTINAL DAMAGE IN SLE}

A 2017 study, conducted on 32 patients, two males and 30 females, revealed a correlation between the presence of neurological and gastrointestinal complications in patients with SLE ${ }^{15}$. Thus, of the $32 \mathrm{pa}-$ tients with SLE, 7 had neurological manifestations in association with all the digestive symptoms. One possible explanation for this correlation could be common pathogenic mechanisms of damage to the two systems or vasculitis. On the other hand, the same study identifies a possible correlation between impaired endocrine function and gastrointestinal lupus. Thus, 9 of the 32 patients had hypothyroidism in association to all digestive symptoms ${ }^{15}$. Further studies are needed to deal with this correlation and thus contribute to elucidate the etiology of this debilitating disease.

\section{Conclusions}

Despite great impact on morbidity and mortality worldwide, as well as the significant costs involved, the etiology of SLE remains uncertain. Even though it is not as frequent as other events, such as the lupus nephritis, gastrointestinal involvement is very important because it can be life-threatening in the absence of appropriate treatment. Damage to the nervous system is also one of the severe manifestations of lupus. If in the case of gastrointestinal damage of SLE specific antibodies have not yet been identified, for psychosis a link with a ribosomal P-protein antibody has been found ${ }^{4}$. Recent studies suggest a possible correlation between neurological and gastrointestinal damage from lupus, association that could be the basis for future studies to elucidate the pathogenesis of autoimmune diseases.

\section{Compliance with Ethics Requirements:}

„The authors declare no conflict of interest regarding this article"

$$
\text { „No funding for this study“ }
$$

\section{References}

1. Mok CC, Lau CS. Pathogenesis of systemic lupus erythematosus. J Clin Pathol 2003;56(7):481-490.

2. Brewer BN, Kamen DL. Gastrointestinal and hepatic disease in systemic lupus erythematosus. Rheum Dis Clin North Am 2018;44(1):165-175.

3. Kakati S, Barman B, Ahmed SU, Hussain M. Neurological manifestations in systemic lupus erythematosus: asingle centre study from North East India. J Clin Diagn Res 2017;11(1):OC05-OC09.

4. Ionescu R. Esentialul in reumatologie. Editura Medicala Amaltea 2006; 348-371.

5. Schur PH, Hahn BH. Epidemiology and pathogenesis of systemic lupus erythematosus. https://www.uptodate.com/ contents/epidemiology-and-pathogenesis-of-systemic-lupus-erythematosus. (accessed 16 March 2019)

6. Pons-Estel GJ, Alarcón GS, Scofield L, Reinlib L, Cooper GS. Understanding the epidemiology and progression of systemic lupus erythematosus. Semin Arthritis Rheum 2010;39(4):257-68.

7. Wallace DJ. Diagnosis and differential diagnosis of systemic lupus erythematosus in adults. https://www.uptodate.com/ 
contents/diagnosis-and-differential-diagnosis-of-systemic-lupus-erythematosus-in-adults. (accessed 14 March 2019)

8. Cong Yu, Gershwin EM, Chang C. Diagnostic criteria for systemic lupus erythematosus: A critical review. Journal of Autoimmunity 2014;48-49:10-13.

9. Plagens-Rotman K, Przybylska R, Adamski Z, Czarnecka-Operacz M. Skin and mucous membranes' manifestations of dermatological diseases within the genital area in females. Postepy Dermatol Alergol 2018;35(2):99-203.

10. Schur PH, Wallace DJ. Musculoskeletal manifestations of systemic lupus erythematosus. https://www.uptodate.com/ contents/musculoskeletal-manifestations-of-systemic-lupus-erythematosus. (accessed 17 March 2019)

11. Mocarzel LOC, Lanzieri PG, Montes RA, Gismondi RAOC, Mesquita CT. Systemic lupus erythematosus: review of cardiovascular aspects. International Journal of Cardiovascular Sciences. 2015; 28(3):251-261.

12. Bomback AS, Appel GB. Diagnosis and classification of renal disease in systemic lupus erythematosus. https://www. uptodate.com/contents/diagnosis-and-classification-of-renal-disease-in-systemic-lupus-erythematosus. (accessed 20 March 2019)

13. Dellaripa PF, Danoff S. Pulmonary manifestations of systemic lupus erythematosus in adults. https://www.uptodate. $\mathrm{com} /$ contents/pulmonary-manifestations-of-systemic-lupus-erythematosus-in-adults. (accessed 21 March 2019)

14. Shoughy SS, Tabbara KF. Ocular findings in systemic lupus erythematosus. Saudi J Ophthalmol 2016;30(2):117-121.

15. Gupta KL, Pattanashetti N, Babu J, Dutta U. Study of gastrointestinal and hepatic manifestations in systemic lupus erythematosus. International Journal of Nephrology and Kidney Failure 2017;3(2). http://dx.doi.org/10.16966/2380-5498.147

16. Tian XP, Zhang X. Gastrointestinal involvement in systemic lupus erythematosus: Insight into pathogenesis, diagnosis and treatment. World J Gastroenterol 2010;16(24):2971-2977.

17. Massarotti EM. Gastrointestinal manifestations of systemic lupus erythematosus. https://www.uptodate.com/contents/ gastrointestinal-manifestations-of-systemic-lupus-erythematosus. (accessed 20 March 2019)

18. Kaul A, Gordon C, Crow MK, et al. Systemic lupus erythematosus. Nat Rev Dis Primers 2016;2:16039.

19. Ebert EC, Hagspiel KD. Gastrointestinal and hepatic manifestations of systemic lupus erythematosus. J ClinGastroenterol 2011;45(5):436.

20. Park FD, Lee JK, Madduri GD, Ghosh P. Generalized megaviscera of lupus: refractory intestinal pseudo-obstruction, ureterohydronephrosis and megacholedochus. World J Gastroenterol 2009;15(28):3555-9.

21. Law ST, Ma KM, Li KK. The clinical characteristics of lupus related protein-losing enteropathy in Hong Kong Chinese population: 10 years of experience from a regional hospital. Lupus 2012; 21(8):840-847.

22. Diaconu C, Balaceanu A, Bartos D. Venous thromboembolism in pregnant woman - a challenge for the clinician. Central European Journal of Medicine. 2013;8(5):548-552.

23. Draghici T, Negreanu L, Bratu OG, et al. Liver abnormalities in patients with heart failure. Arch Balk Med Union. 2018;53(1):76-81.

24. Alves SC, Fasano S, Isenberg DA. Autoimmune gastrointestinal complications in patients with systemic lupus erythematosus: case series and literature review. Lupus 2016;25(14):1509-1519.

25. Mogoanta SS, Costache A, Mutiu G, et al. A nonfunctional neuroendocrine tumor of the pancreas - a case report.
Romanian Journal of Morphology and Embriology 2015;56(2 Suppl.):511-519.

26. Diaconu C, Balaceanu A, Morosan E. Sepsis biomarkers: past, present and future. Farmacia 2015;63(6):811-815.

27. Pott Júnior H, Amate Neto A, Teixeira MA, Provenza JR. Ascites due to lupus peritonitis: a rare form of onset of systemic lupus erythematosus. Rev Bras Reumatol 2012; 52(1):116-9.

28. Diaconu C, Dumitru N, Fruntelata A, Lacau S, Bartos D. Apical hypertrophic cardiomyopathy: the ace-of-spades as the disease card. Acta Cardiologica Sinica 2015;31(1):1:83-86.

29. Watanabe R, Fujii H, Kamogawa Y, et al. Chronic lupus peritonitis is characterized by the ascites with a large content of interleukin-6. Tohoku J Exp Med 2015; 235(4):289-94.

30. Schur PH. Neurologic manifestations of systemic lupus erythematosus. https://www.uptodate.com/contents/neurologic-manifestations-of-systemic-lupus-erythematosus. (accessed 19 March 2019)

31. Schur PH. Diagnostic approach to the neuropsychiatric manifestations of systemic lupus erythematosus. https://www. uptodate.com/contents/diagnostic-approach-to-the-neuropsychiatric-manifestations-of-systemic-lupus-erythematosus. (accessed 22 March 2019)

32. Hanly JG, Su L, Farewell V, et al. Prospective study of neuropsychiatric events in systemic lupus erythematosus. J Rheumatol 2009; 36(7):1449-59.

33. Mikdashi J, Handwerger B, Langenberg P, et al. Baseline disease activity, hyperlipidemia, and hypertension are predictive factors for ischemic stroke and stroke severity in systemic lupus erythematosus. Stroke 2007;38(2):281-5.

34. Mok CC, Ho LY, To CH. Annual incidence and standardized incidence ratio of cerebrovascular accidents in patients with systemic lupus erythematosus. Scand J Rheumatol 2009; 38(5):362-8

35. Nojima J, Kuratsune H, Suehisa E, et al. Strong correlation between the prevalence of cerebral infarction and the presence of anti-cardiolipin/beta2-glycoprotein I and anti-phosphatidylserine/prothrombin antibodies-Co-existence of these antibodies enhances ADP-induced platelet activation in vitro. Thromb Haemost 2004; 91(5):967-76.

36. González-Duarte A, Cantú-Brito CG, Ruano-Calderón L, García-Ramos G. Clinical description of seizures in patients with systemic lupus erythematosus. Eur Neurol 2008; 59(6):320-3.

37. Fodor K, Tit DM, Pasca B, et al. Long-term resveratrol supplementation as a secondary prophylaxis for stroke. Oxidative Medicine and Cellular Longevity 2018;2018:1-10, ID 4147320 .

38. Bertsias GK, Ioannidis JP, Aringer M, et al. EULAR recommendations for the management of systemic lupus erythematosus with neuropsychiatric manifestations: report of a task force of the EULAR standing committee for clinical affairs. Ann Rheum Dis 2010;69(12):2074-82.

39. Bungau S, Tit DM, Fodor K, et al. Aspects regarding the pharmaceutical waste management in Romania. Sustainability 2018;10(8):2788.

40. Lewis M, Gibson T. Systemic lupus erythematosus with recurrent Guillain-Barré-like syndrome treated with intravenous immunoglobulins. Lupus 2003;12(11):857-9.

41. Vina ER, Fang AJ, Wallace DJ, Weisman MH. Chronic inflammatory demyelinating polyneuropathy in patients with systemic lupus erythematosus: prognosis and outcome. Semin Arthritis Rheum 2005;35(3):175-84. 